\title{
Roles of interfaces in nanostructured composites: nanocatalysts, sponge crystals and thin films
}

\author{
Kei INUMARU ${ }^{\dagger}$ \\ Department of Applied Chemistry, Graduate School of Engineering, Hiroshima University, \\ 1-4-1 Kagamiyama, Higashi-Hiroshima, Hiroshima 739-8527, Japan
}

Interfaces are important in the functionality of materials with composite structures. Focusing mainly on our studies, this article provides an overview of the functionality that can be achieved by the careful design of interfaces in inorganic composites. Molecular selective photocatalysts have been realized by developing nanostructures, in which photocatalytically active metal oxide particles are surrounded by mesoporous silica. Such composites structure achieved combined function of molecular selective adsorption and photocatalytic decomposition. Solid acid catalysts that are active in water have been realized by exploiting the nanostructure of mesoporous silica. Catalytically active inorganic molecules such as heteropolyacids have been anchored on the walls within the pores of hydrophobic organic layers. The resulting nanocomposite exhibited high acid catalytic activity in water. Sponge crystals are a more recently discovered class of porous crystals. We discuss their structure, and propose revised classifications of microporous crystals, mesocrystals and sponge crystals. Thin films of metal nitrides $\operatorname{such}$ as $\mathrm{Sr}_{2} \mathrm{~N}$ and metal oxides have been prepared by molecular beam epitaxy and pulsed laser deposition. The effects of the interface between the film and substrate are discussed.

(C2016 The Ceramic Society of Japan. All rights reserved.

Key-words : Photocatalyst, Catalyst, Mesoporous silica, Sponge crystals, Nitride, Ferromagnetism

[Received May 1, 2016; Accepted July 22, 2016]

\section{Introduction}

Designing composite structures has for many years been an intensively studied field of materials science and chemistry. The nanoscale design of the structures of composite materials is a key strategy in various research fields. Composites contain two or more components or domains. As a consequence, they contain interfaces between these components.

A useful strategy for developing composites is to design interactions through these interfaces. To understand and design various functionality into composites, it is useful to consider what each side of an interface "exchanges", "transfers", or "communicates" through the interface. Components on either side of an interface in a composite can interact by:

(i) transfer of molecules through the interface,

(ii) transfer of electrons and/or holes through the interface,

(iii) inducing electric carriers through a strong electric field at the interface,

(iv) mechanical forces at the interface, for example strain at an epitaxial interface,

(v) weak interactions like van der Waals forces at the interface,

(vi) interactions between magnetic spins.

Figure 1 shows a schematic for classifying composites, according to the interaction at their interfaces. For example, if only specific molecules can transfer through the interface, then combining this with other functionality, such as catalysis and photocatalysis, could realize molecular selective (photo)catalysts [Fig. 1(a), case (i) in the above classification]. Alternatively, electrons and holes could transfer through the interface between

\footnotetext{
Corresponding author: K. Inumaru; E-mail: inumaru@hiroshimau.ac.jp
}

(a)

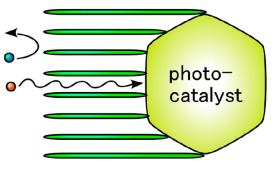

(c)

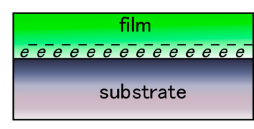

(b)

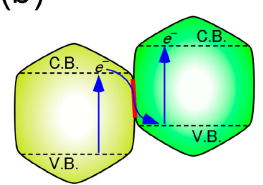

(d)

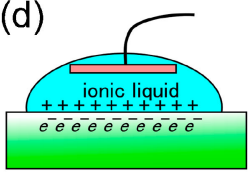

(e)

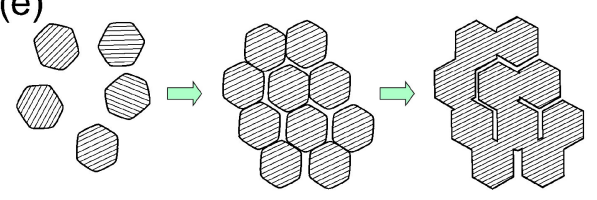

(f)

(g)
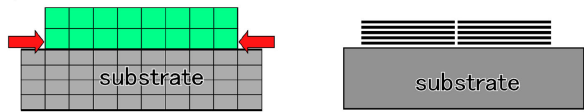

Fig. 1. Schematic illustrations of functional interfaces: (a) molecular selective (photo)catalysts, (b) electron transfer between semiconductor particles in Z-scheme photocatalysts, (c) two-dimensional electrons induced on an epitaxial interface, (d) electron carriers induced by a strong electrical field on a semiconductor surface, (e) formation of a sponge crystal by epitaxial self-assembly of nanocrystallites, (f) epitaxial film subjected to strain from a single crystal substrate, $(\mathrm{g})$ uniaxial growth of a layered compound on a smooth substrate surface. 
particles [Fig. 1(b), case (ii)], or the interface between a thin film and substrate. Photocatalysts that operate by the so-called " $\mathrm{Z}$ scheme" fall into the category shown in Fig. 1(b). ${ }^{1)}$ When two kinds of semiconductor particles are in contact with each other, one semiconductor may absorb photons to generate excited electrons in the conduction band, which then transfer to the valence band of the other semiconductor, through the interface between the particles [case (ii)]. Electrons induced at the interface of an insulating substrate and epitaxial thin film fall into the category in Fig. 1(c) [case (iii)]. ${ }^{2)}$ A strong electric field at the interface can induce charge carriers at the semiconductor surface, as shown in Fig. 1(d). The electrical double layer at the interface of a solid and ionic liquid produces an electric field. This field can be sufficiently strong to bring about the transition from a semiconducting surface to a metallic conduction [case (iii)]. ${ }^{3), 4)}$ Epitaxy between inorganic crystals is another important phenomenon. Nanocrystallites can aggregate in the same crystal direction, with their connection arising homoepitaxially by local dissolution-precipitation. This yields a "sponge crystal" [Fig. 1(e)], as we discovered in 1996, and we named this process "epitaxial self-assembly" ${ }^{6)}$ Hetero-epitaxial growth of thin films on crystalline substrates can also significantly affect the structure and physical properties of the crystalline thin film. For example, the metal-insulator transition temperature of $\mathrm{VO}_{2}$ epitaxial thin films can reportedly be controlled by the tensile or compression strain of the substrate [Fig. 1(f), case (iv)]. ${ }^{7)}$ Alternatively, if the interaction between the film and substrate is weak, the thin film orientation can be dictated by the nature of the crystalline phase. The basal plane of compounds with layered structures tends to orientate parallel to the substrate surface [Fig. 1(g), case (v)]. This has been exploited to prepare uniaxially oriented thin films of the layered compound $\mathrm{Sr}_{2} \mathrm{~N}^{8}{ }^{8}$ This compound is isostructural with $\mathrm{Ca}_{2} \mathrm{~N}$; a two-dimensional electride compound that has attracted much recent attention. ${ }^{9)}$ Through the epitxial interface, magnetic interaction brings about 'exchange bias', in which directions of magnetization of ferromagnetic thin films are controlled by the interaction with the spins at the surface of antiferromagnetic substrate [case (vi)]. ${ }^{10)}$ Another area of thin film synthesis is in preparing solid solutions. This involves two or more components being supplied in atomic form to the substrate, to achieve mixing of the components at the atomic level.

In this article, focusing mainly on our studies, we provide an overview of the role of interfaces in composites, to achieve various functionality, and to understand the effects of interfaces on the structure and properties of solids.

\section{Molecular selective photocatalysts realized by composites with nanoscale structures}

$\mathrm{TiO}_{2}$ is a versatile photocatalyst. ${ }^{11)}$ It can potentially be applied in the production of hydrogen from water, and in the removal of organic contaminants from air and water. ${ }^{12)}$ In environmental purification applications, $\mathrm{TiO}_{2}$ absorbs ultraviolet wavelengths to generate active species such as hydroxyl radicals and $\mathrm{O}_{2}{ }^{-}$. These active species react with organic contaminants, decomposing them to $\mathrm{CO}_{2}$ and $\mathrm{H}_{2} \mathrm{O}$. $\mathrm{TiO}_{2}$ as a photocatalyst has no molecular selectivity, so non-selectively decomposes all organic molecules. This results from the non-selective nature of the active species generated at the surface of the photocatalyst. This can be beneficial, since all organic contaminants can be removed by a single photocatalyst. However, the non-selectivity of the $\mathrm{TiO}_{2}$ photocatalyst can be detrimental when concentrated co-existing species suppress the reaction of a dilute target contaminant. Physiologically active molecules often retain their activity at very low concentrations. A high selectivity toward these molecules is necessary to achieve their complete decomposition by photocatalysis. Molecular selective photocatalysis was first proposed around $2000 .{ }^{13)}$ Studies of this including our own works soon followed, and were built on by many subsequent studies in the following decade. A review article on this field was published in 2013. ${ }^{14}$

\subsection{Combining molecular selective adsorption and photocatalysis}

A simple and effective strategy for realizing molecular selective photocatalysis is to combine molecular selective adsorption and photocatalysis. An early photocatalyst model is shown in Fig. 2. ${ }^{13)}$ Its structure is formed on the surface of a flat substrate. Domains affording molecular selective adsorption sites and domains that are photocatalytically active are located to allow molecules to transfer from the former to the latter.

\subsection{Octyl group-grafted $\mathrm{TiO}_{2}\left(\mathrm{C} 8-\mathrm{TiO}_{2}\right)$ and octyl group-grafted $\mathrm{TiO}_{2} /$ mesoporous silica (C8- $\mathrm{TiO}_{2}-\mathrm{MPS}$ )}

A high surface area promotes high photocatalytic activity, so small crystals and porous materials are advantageous as components of photocatalysts. We exploited a simple strategy to realize molecular selective photocatalysis. Organic molecules were grafted directly on the surface of photocatalytically active particles. This strategy imparted molecular selectivity on the photocatalyst surface. ${ }^{15)}$ The target molecule was nonylphenol; an endocrine disrupting chemical that is active for fish. Nonylphenol is amphipathic. It has a large branched nonyl group as the hydrophobic part, and a phenolic hydroxyl group as the hydrophilic part.

Commercially available $\mathrm{P} 25 \mathrm{TiO}_{2}$ was used as the photocatalyst, as it is well known to be highly active. Figure 3(a) shows a $\mathrm{TiO}_{2}$ surface was functionalized with hydrophobic octyl groups $\left(\mathrm{C} 8-\mathrm{TiO}_{2}\right)$. Photocatalytic activity was tested using an aqueous solution containing $2 \mathrm{ppm}$ nonylphenol and $1000 \mathrm{ppm}$ phenol. The solution contained a coexisting molecule (phenol) with a concentration of 500 times higher than the target molecule (nonylphenol). Figure 3(b) shows the time course of the nonylphenol concentration. When the photocatalyst was added to the solution, the nonylphenol concentration noticeably decreased by adsorption. Photoirradiation was then commenced, upon which the nonylphenol concentration decreased rapidly. Nonylphenol was completely removed after several hours, in the presence of concentrated coexisting phenol.

For comparison, $\mathrm{P} 25 \mathrm{TiO}_{2}$ without surface modification was also tested under the same conditions. The results are shown inset in Fig. 3(b). The decomposition rate of nonylphenol decreased significantly after $1 \mathrm{~h}$ of photoirradiation, and significant nonylphenol remained after prolonged photoirradiation, because of the presence of concentrated phenol. This molecular selective photocatalyst exhibited very high activity, because the $\mathrm{TiO}_{2}$ particles were highly crystalline and had high photocatalytic activity.

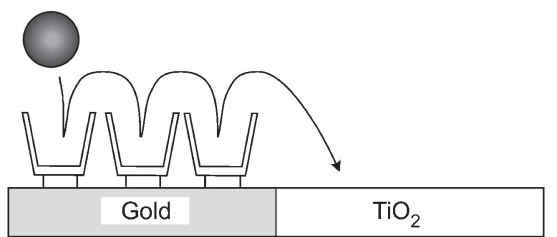

Fig. 2. Early concept of a molecular selective photocatalytic system. 
(a)

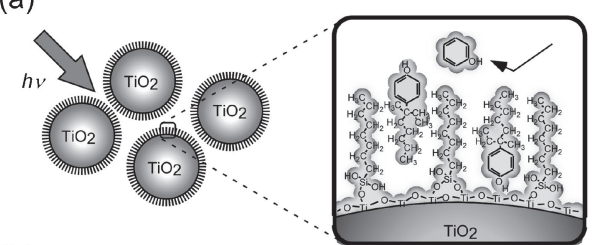

(b)

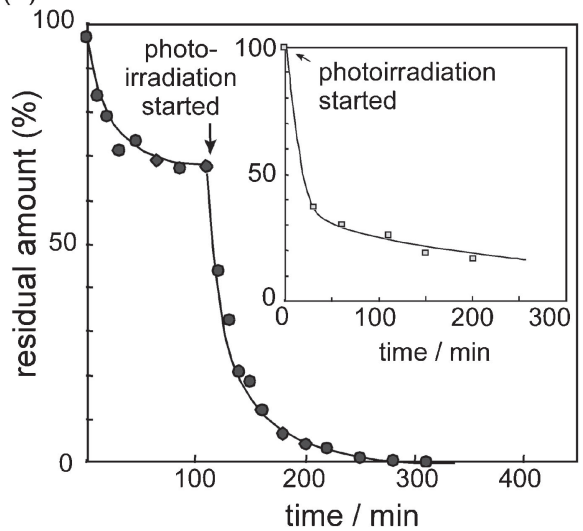

Fig. 3. (a) Illustration of $\mathrm{C} 8-\mathrm{TiO}_{2}$, (b) time course of nonylphenol concentration during the photocatalytic decomposition by $\mathrm{C} 8-\mathrm{TiO}_{2}$ in the presence of a high phenol concentration $(500 \mathrm{ppm})$. The inset shows the time course of photocatalysis by pristine $\mathrm{TiO}_{2}$ under the same conditions.

Despite this high activity and molecular selectivity, the durability of the photocatalyst was poor. The photocatalytic reaction gradually decomposed the surface functionalization, and molecular selectivity deteriorated with prolonged photoirradiation.

We synthesized another nanostructured composite photocatalyst, in which hydrophobic organic groups were grafted inside the pore walls of $\mathrm{TiO}_{2}$-supported mesoporous silica $\left(\mathrm{C} 8-\mathrm{TiO}_{2}-\right.$ MPS). ${ }^{16)}$ The molecular selectivity of this photocatalyst was high, but its photocatalytic activity was low, because of low $\mathrm{TiO}_{2}$ crystallinity and loading (approximately $13 \mathrm{wt} \%$ maximum).

The results of these studies indicate that (i) combining molecular selective adsorption and photocatalysis is very effective, (ii) pre-formed highly crystalline $\mathrm{TiO}_{2}$ particles are preferable as the photocatalytic moiety, and (iii) the photocatalyst should contain only inorganic materials, to maximize catalyst stability.

\section{3 $\mathrm{TiO}_{2}$ particle-mesoporous silica composites}

This strategy assigns the roles of molecular selective adsorption and photocatalytic activity to mesoporous silica and preformed well-crystalline $\mathrm{TiO}_{2}$ particles, respectively. ${ }^{17)-19)}$ The $\mathrm{TiO}_{2}$ particle size was approximately $20-30 \mathrm{~nm}$, which was much larger than the pore diameter of mesoporous silica of approximately $3 \mathrm{~nm}$. Thus, the $\mathrm{TiO}_{2}$ particles could not be loaded into the pores. An alternative structure was needed to combine these two functionalities. This was achieved in a composite consisting of $\mathrm{TiO}_{2}$ particles surrounded by mesoporous silica, as shown in Fig. 4(a). ${ }^{20)}$ This structure was synthesized by precipitating mesoporous silica using the sol-gel method, in a solution containing dispersed $\mathrm{TiO}_{2}$ particles. Transmission electron microscopy (TEM) images of the composite are shown in Fig. 4(b). The $\mathrm{TiO}_{2}$ content in this composite was as high as $60 \mathrm{wt} \%$.

Results of molecular selective photocatalytic tests are shown in Fig. 4(c). An aqueous solution containing four alkylphenols was subjected to photocatalytic reaction. After adding the composite photocatalyst to the solution, decreases in concentrations due to selective adsorption were observed for nonlylphenol and heptyl-

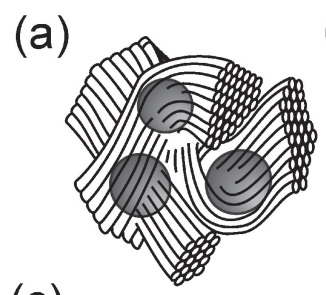

(b)
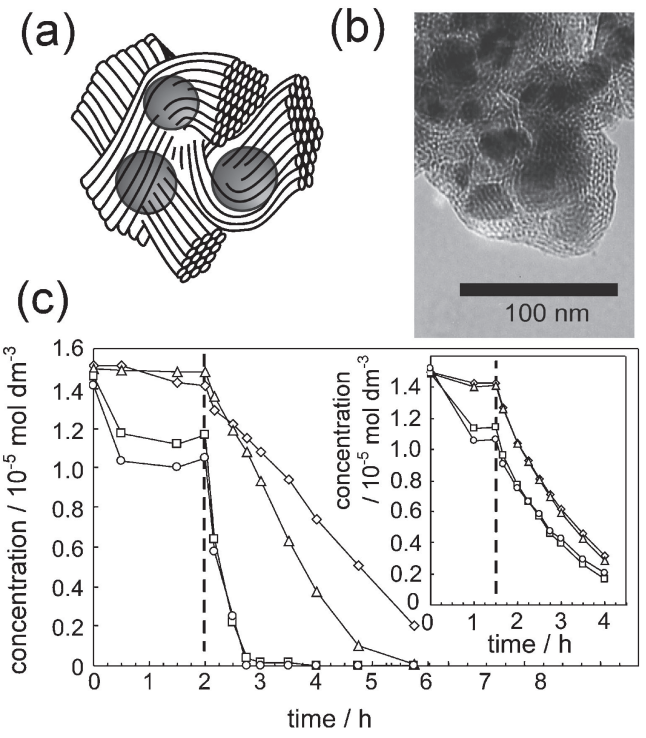

Fig. 4. (a) Schematic illustration, (b) TEM images of $\mathrm{TiO}_{2}$ particlemesoporous silica composite, and (c) time course during the photocatalytic decomposition of mixed alkylphenols in aqueous solution. The inset shows the time course of photocatalysis by a mechanical mixture of pristine $\mathrm{TiO}_{2}$ and mesoporous silica, under the same conditions. $\bigcirc$, nonylphenol; $\square$, heptylphenol; $\triangle$, propylphenol; $\diamond$, phenol.

phenol, because of their larger alkyl groups. After photoirradiation, the preferentially adsorbed nonylphenol and heptylphenol were decomposed much faster than the other two phenols. Another experiment demonstrated the importance of molecular selectivity: in the presence of phenol with a concentration 100 times larger than those of nonylphenol and heptylphenol, the two target compounds were completely decomposed by the molecular selective photocatalyst, but were unable to be so when using pristine $\mathrm{TiO}_{2}$ as the photocatalyst.

These reports stimulated further studies on molecular selective photocatalysis, and a review on this topic was recently published. ${ }^{14)}$

\section{Nanoscale organic-inorganic hybrid catalysts based on mesoporous silica}

\subsection{Solid acid catalysts operating in water}

Mesoporous silica has a characteristic nanoscale structure, with uniform ordered pores of diameter of several nanometers. Many studies have exploited this structure to realize various functionalities. Mesoporous silica has a high surface area, and many studies have explored its applications in catalysis. ${ }^{21)}$ The innerpore walls of mesoporous silica are often functionalized by chemical modification. The following highly active solid acid catalyst has a nanostructure based on mesoporous silica. Organic groups and inorganic molecules were grafted on the inner-pore walls.

Solid acid catalysts have benefits compared to liquid acids such as $\mathrm{H}_{2} \mathrm{SO}_{4}$, because solid catalysts are easily separated from solution, and are less corrosive to metallic reactors. In aqueous solutions, only a limited number of solid acid catalysts are workable, because acidic protons on solid surfaces are deactivated in water. In 1981, a hydrophobic zeolite catalyst (H-ZSM5) was reported to be active in aqueous solution. ${ }^{22)}$ Another solid acid catalyst active in aqueous solution is the acidic inorganic salt $\mathrm{Cs}_{2.5} \mathrm{H}_{0.5} \mathrm{PW}_{12} \mathrm{O}_{40}$. It was reported in 1997 that this catalyst exhibited the highest reaction rate per acidic proton at the 


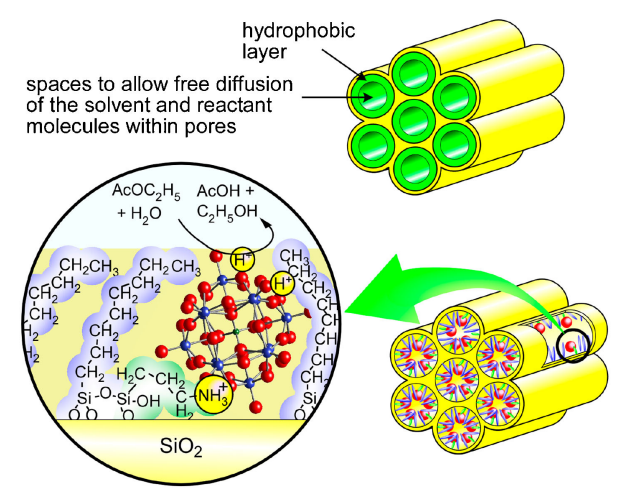

Fig. 5. Nanostructure of a solid acid catalyst active in aqueous solution.

time. ${ }^{23), 24)}$ These active catalysts both possess high surface hydrophobicity. H-ZSM-5 is a siliceous zeolite with highly hydrophobic channels. $\mathrm{Cs}_{3} \mathrm{PW}_{12} \mathrm{O}_{40}$ surfaces are hydrophobic.

\subsection{Nanoscale design strategy}

Previous studies hinted at the potential of acidic protons located in hydrophobic reaction fields. However, if acidic protons are completely buried in a hydrophobic environment, water and reactant molecules cannot access the active sites. Grafting long hydrophobic chains on pore walls inhibits liquid water from intruding into pore spaces of mesoporous silica. ${ }^{25)}$ Thus, the nanostructure in Fig. 5 was designed. ${ }^{26)}$ Spaces were left at the centers of pores, to allow free diffusion of the solvent and reactant molecules within pores. Active acidic protons were required to be exposed to the interface between the aqueous solvent and hydrophobic layer that was grafted on the inner pore wall. Thus, octyl groups and $\mathrm{H}_{3} \mathrm{PW}_{12} \mathrm{O}_{40}$ heteropolyacid inorganic molecules were used as the hydrophobic groups and catalytically active acidic inorganic species, respectively. The size of the inorganic molecule was approximately $1 \mathrm{~nm}$, and the octyl group length was comparable. Thus, a hydrophobic reaction environment formed around the inorganic molecules, and acidic protons on the inorganic molecules were exposed to the interface of the aqueous phase intruding into pores, as shown in Fig. 5. Aminopropyl groups were grafted, to anchor inorganic molecules on pore walls. One inorganic molecule was anchored through one ammonium group formed by reaction with one acidic proton. Therefore, two protons per inorganic molecule remained unreacted, which was confirmed by the adsorption of basic pyridine molecules on the catalyst.

\subsection{Catalytic performance}

Table 1 summarizes the results of the catalytic reactions. The composite catalyst exhibited the highest reaction rate per acidic proton. The activity per acidic proton was up to six times higher than that of sulfuric acid, a commercially used liquid acid. The concept proposed in this study, namely of combining a hydrophobic reaction field and inorganic acidic molecules on the nanoscale, was used in subsequent studies of acid catalysts in aqueous media. ${ }^{27)}$

\section{Sponge crystals: a new class of porous crystals}

Before 1996, studies had been reported about metal oxides particles aggregates having characteristic shapes. For example, Sugimoto et al. reported that iron oxide formed pseudocubeshaped aggregates of crystallites. ${ }^{28)}$ The constituent crystallites had the same crystal orientation in an aggregate, but no epitaxial
Table 1. Catalytic activity for ethyl acetate hydrolysis in water

\begin{tabular}{|c|c|c|c|c|}
\hline \multirow[b]{2}{*}{ Catalyst } & \multirow[b]{2}{*}{$\begin{array}{l}\text { State of } \\
\text { catalysts }\end{array}$} & \multirow[b]{2}{*}{$\begin{array}{l}\text { Acidity of } \\
\text { catalysts }^{\text {a) }}\end{array}$} & \multicolumn{2}{|c|}{ Catalytic activity } \\
\hline & & & $\begin{array}{l}\text { Per cat. } \\
\text { weight }^{\text {b) }}\end{array}$ & $\begin{array}{c}\text { Per acidic } \\
\text { protons }^{c)}\end{array}$ \\
\hline Composite ${ }^{\mathrm{d})}$ & solid & 0.091 & 25.1 & 275 \\
\hline $\mathrm{Cs}_{2.5} \mathrm{H}_{0.5} \mathrm{PW}_{12} \mathrm{O}_{40}{ }^{\mathrm{e})}$ & solid & 0.15 & 30.1 & 200 \\
\hline $\mathrm{H}-\mathrm{ZSM}-5^{\mathrm{e})}$ & solid & 0.8 & 27.6 & 70 \\
\hline H-Y zeolite $\left.{ }^{e}\right)$ & solid & 2.6 & 0 & 0 \\
\hline $\mathrm{H}_{2} \mathrm{SO}_{4}{ }^{\mathrm{e})}$ & liquid & 19.8 & 992 & 46 \\
\hline
\end{tabular}

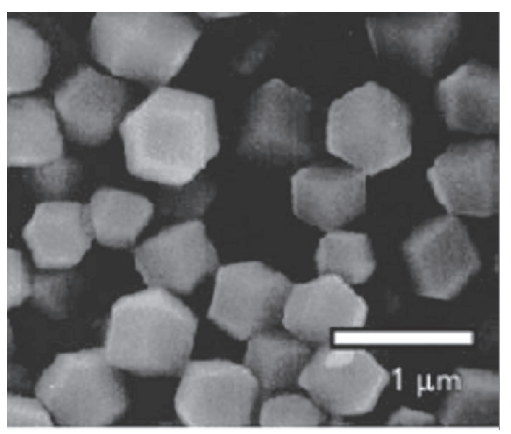

Fig. 6. SEM image of $\left(\mathrm{NH}_{4}\right)_{3} \mathrm{PW}_{12} \mathrm{O}_{40}$ sponge crystals.

connections formed between the crystallites, unlike the sponge crystals as is described below. At the time there was no report that epitaxial connections forms between crystallites in an aggregate and the whole aggregate is coherent in terms of X-ray diffraction.

In 1996, we reported the ordered structure of porous crystal of $\left.\left(\mathrm{NH}_{4}\right)_{3} \mathrm{PW}_{12} \mathrm{O}_{40}{ }^{6}\right)$ It exhibited high porosity, but its crystal structure contained no interstitial spaces or built-in pores, such as occur within zeolites. ${ }^{29), 30)}$ In 2006, we reviewed our studies of this compound, and named this class of porous crystals, sponge crystals. ${ }^{5)}$ The definition of a sponge crystal in 2006 was:

"Sponge crystals" are single crystals containing continuous voids, and unlike zeolites, have no intrinsic structural pores. To comply with this definition of "sponge crystals", the crystal structure of a compound should not have intrinsic pores defined by the crystal structure itself, therefore ruling out zeolites as sponge crystals.'

$\left(\mathrm{NH}_{4}\right)_{3} \mathrm{PW}_{12} \mathrm{O}_{40}$ crystals precipitated at elevated temperatures comply with this definition. Figure 6 shows an SEM image of $\left(\mathrm{NH}_{4}\right)_{3} \mathrm{PW}_{12} \mathrm{O}_{40}$ sponge crystals. Each dodecahedral crystal was highly microporous. The formation process is shown in Fig. 1(e). The ordered porous crystals form by the self-assembly of nanocrystallites. Epitaxial connections form between them by dissolution-precipitation at interfaces, leaving spaces between crystallites as pores. X-ray diffraction and various microscopy techniques supported the characterization of this structure and its formation mechanism. In 1996, we named this crystallite selfassembly mechanism "epitaxial self-assembly". ${ }^{6}$ Sponge crystals are coherent in terms of X-ray diffraction, because the crystallites are epitaxially connected with each other. (After defining the term "epitaxial self-assembly" in 1996, the same term began to be used with a different meaning in $2003,{ }^{31)}$ which has caused some confusion.)

After our report of epitaxial self-assembly, Colfen et al. proposed the concept of "mesocrystals". ${ }^{32)}$ This is a wider category than sponge crystals. Mesocrystals have a characteristic shape, which reflects the shape of their constituent crystallites. Thus, 


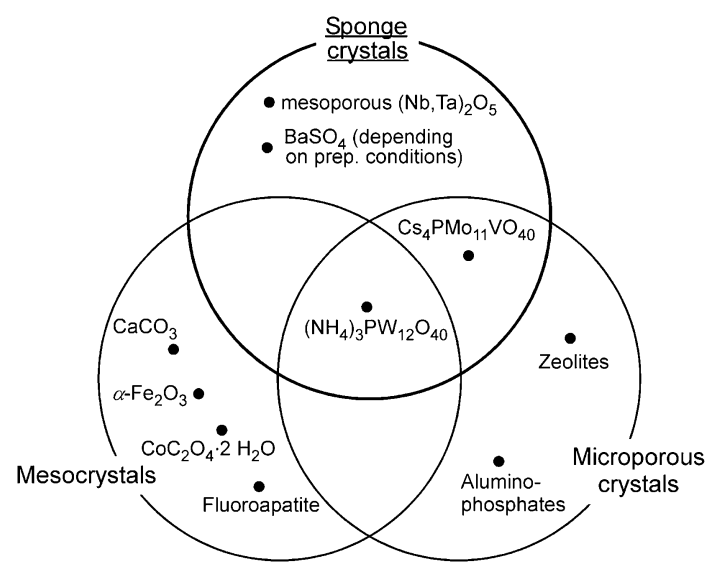

Fig. 7. Relationship between microporous crystals, mesocrystals, and sponge crystals. This chart was revised from that in Ref. 5. Microporous crystals are classified into two categories: typical porous crystals like zeolites with intrinsic structural pores (i.e. built-in pores), and pores in sponge crystals which are not intrinsic structural pores. Some sponge crystals such as $\left(\mathrm{NH}_{4}\right)_{3} \mathrm{PW}_{12} \mathrm{O}_{40}$ are formed by aggregation of nanocrystallites, and are accordingly classified as mesocrystals. More recently, ordered mesoporous $(\mathrm{Nb}, \mathrm{Ta})_{2} \mathrm{O}_{5}$ was reported by Kondo et al., which is classified as a sponge crystal but belongs to neither the mesocrystal nor microporous crystal family (See text).

the orientation of the constituent crystallites is the same in a mesocrystal. The main difference between a sponge crystal and mesocrystal is that the constituent crystallites in a mesocrystal are not necessarily coherent, in terms of X-ray diffraction. A sponge crystal is coherent for the whole crystal, in terms of X-ray diffraction. In this sense, materials that can be categorized as mesocrystals can be found in earlier studies, such as iron oxide $\left(\alpha-\mathrm{Fe}_{2} \mathrm{O}_{3}\right)$ aggregates with characteristic shapes. ${ }^{28)}$ The constituent crystallites have the same crystal orientation, but are not coherent in terms of X-ray diffraction.

More recently, sponge crystals with mesopores have been reported. Porous $(\mathrm{Nb}, \mathrm{Ta})_{2} \mathrm{O}_{5}$ had an ordered structure $\left.{ }^{33}\right)$ TEM images showed that all parts of this material had the same crystal orientation. Their TEM images appear to show $(\mathrm{Nb}, \mathrm{Ta})_{2} \mathrm{O}_{5}$ grains connected epitaxially with each other. According to the definition of sponge crystal, this mesoporous oxide should be classified to sponge crystal. It is a subtle point whether or not the mesoporous $(\mathrm{Nb}, \mathrm{Ta})_{2} \mathrm{O}_{5}$ is a member of mesocrystals. The constituent crystallites in the $\mathrm{Nb}_{2} \mathrm{O}_{5}$ material do not appear to have a characteristic crystal habit, so we consider that the material is a sponge crystal, but not a mesocrystal.

A new classification revised from that in Ref. 5 is shown in Fig. 7. The common class of mesocrystals and microporous crystals includes $\left(\mathrm{NH}_{4}\right)_{4} \mathrm{PW}_{12} \mathrm{O}_{40}$ sponge crystals. The above mentioned mesoporous $\mathrm{Nb}_{2} \mathrm{O}_{5}$ sponge crystal belongs to neither mesocrystals nor microporous crystals. Continuous efforts have been made to find new members of such material classes. The classification of these crystals has also been discussed in a review. ${ }^{34)}$

\section{Thin films: effects of interaction from substrates}

\subsection{Uniaxially oriented growth of the layered nitride, $\mathrm{Sr}_{2} \mathrm{~N}^{8)}$}

As shown in Fig. 1(g), when the interaction between thin films and substrates is weak, such as in layered compounds, thin films tend to grow with a uniaxial orientation. The basal plane of the layered structure tends to become parallel to the substrate surface.

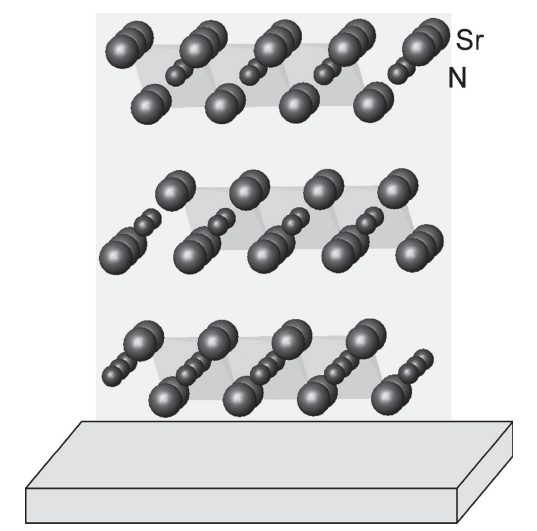

Fig. 8. $\mathrm{Sr}_{2} \mathrm{~N}$ thin film grown on a flat substrate.

This phenomenon could be exploited to prepare uniaxially oriented thin films of the layered nitride $\mathrm{Sr}_{2} \mathrm{~N}$ on $\mathrm{MgO}(001)$ substrate, as shown in Fig. 8.

The compound $\mathrm{Sr}_{2} \mathrm{~N}$ has been known for a long time. ${ }^{35), 36)}$ As shown in Fig. $8, \mathrm{Sr}_{2} \mathrm{~N}$ crystallizes in an anti- $\mathrm{CdCl}_{2}$ structure. It is isostructural to $\mathrm{Ca}_{2} \mathrm{~N}$, which has attracted much attention as a two-dimensional electride compound. ${ }^{9)} \mathrm{Sr}_{2} \mathrm{~N}$ is also a two-dimensional electride. In 2004, we measured the electronic conductivity of $\mathrm{Sr}_{2} \mathrm{~N}$, in the direction parallel to the layers of the compound ${ }^{8)}$ The resistivity was as low as that of Sr metal, and its temperature dependence was metallic. This supported the concept of two-dimensional free electrons, which was proposed for $\mathrm{Ca}_{2} \mathrm{~N}$ and $\mathrm{Sr}_{2} \mathrm{~N}$. ${ }^{8), 37)}$

\subsection{Effects of epitaxial interfaces on substrates}

As discussed in the introduction, exploiting the strain from substrates is a promising strategy for controlling the physical properties of thin films. The physical properties are tunable, from those of the bulk crystal. For instance, it has been reported that the metal-insulator transition temperature of $\mathrm{VO}_{2}$ thin films can be tuned by the strain of the substrate. ${ }^{7}$ We also reported that the growth orientation of $\mathrm{CrN}$ epitaxial thin films on $\mathrm{MgO}(001)$ and $\alpha-\mathrm{Al}_{2} \mathrm{O}_{3}(0001)$ substrates affected the antiferromagnetic transition of $\mathrm{CrN}$. This was possibly due to strain and/or constrain (i.e. the effect of substrates fixing the positions of atoms at their interfaces, preventing them from changing their interatomic distances) from the substrate. ${ }^{38)}$ These examples demonstrate that transitions are accompanied by a change in structural distortion or symmetry.

\subsection{Solid solution thin films}

Thin film synthesis is useful for preparing solid solutions, because two or more components can be supplied in atomic form to the substrate, to achieve mixing of the components in atomic level. We investigated metal nitride solid solutions, including $\mathrm{Ti}_{1-x} \mathrm{Ni}_{x} \mathrm{~N}_{y}{ }^{39)}$ and $\mathrm{Cr}_{x} \mathrm{Ti}_{1-x} \mathrm{~N}^{40), 41)}$ The latter exhibited ferromagnetism and characteristic magnetoresistance behavior. The mechanism was discussed by means of band calculations by a theorist. ${ }^{42)}$ The behavior of the nitride was compared with that of the colossal magnetoresistance (CMR) of the oxide $\mathrm{La}_{1-x} \mathrm{Sr}_{x} \mathrm{MnO}_{3}{ }^{40}$ )

\section{Conclusions}

The effects of interfaces were overviewed in various inorganic materials and composites, largely consisting of our studies over the last two decades. The materials and phenomena discussed range from porous materials as (photo)catalysts, to the self- 
assembly of nanocrystallites, to epitaxial thin films on single crystal substrates. The important point is to control the structure of an interface at the atomic or molecular level, even though characterization of the interface structure is often difficult. Designing functionality into interfaces is a promising strategy for exploring new phenomenon in solid state materials and nanostructured composites.

Acknowledgment A part of this work was supported by the Advanced Catalytic Transformation Program for Carbon Utilization (ACT-C), Japan Science and Technology Agency (JST), and by JSPS KAKENHI Grant Nos. JP25288108 and JP15K14128.

\section{References}

1) A. Kudo, MRS Bull., 36, 32-38 (2011).

2) A. Ohtomo and H. Y. Hwang, Nature, 427, 423-426 (2004).

3) H. T. Yuan, H. Shimotani, A. Tsukazaki, A. Ohtomo, M. Kawasaki and Y. Iwasa, Adv. Funct. Mater., 19, 1046-1053 (2009).

4) K. Ueno, S. Nakamura, H. Shimotani, A. Ohtomo, N. Kimura, T. Nojima, H. Aoki, Y. Iwasa and M. Kawasaki, Nat. Mater., 7, 855-858 (2008).

5) K. Inumaru, Catal. Surv. Asia, 10, 151-160 (2006).

6) K. Inumaru, H. Nakajima, T. Ito and M. Misono, Chem. Lett., 25, 559-560 (1996).

7) Y. Muraoka and Z. Hiroi, Appl. Phys. Lett., 80, 583-585 (2002).

8) K. Inumaru, Y. Kuroda, K. Sakamoto, M. Murashima and S. Yamanaka, J. Alloys Compd., 372, L1-L3 (2004).

9) K. Lee, S. W. Kim, Y. Toda, S. Matsuishi and H. Hosono, Nature, 494, 336-340 (2013).

10) J. Nogues and I. K. Schuller, J. Magn. Magn. Mater, 192, 203-232 (1999).

11) A. Fujishima and K. Honda, Nature, 238, 37-38 (1972).

12) K. Hashimoto, H. Irie and A. Fujishima, Jpn. J. of Appl. Phys. Part 1, 44, 8269-8285 (2005).

13) S. Ghosh-Mukerji, H. Haick, M. Schvartzman and Y. Paz, J. Am. Chem. Soc., 123, 10776-10777 (2001).

14) M. A. Lazar and W. A. Daoud, RSC Advances, 3, 4130-4140 (2013).

15) K. Inumaru, M. Murashima, T. Kasahara and S. Yamanaka, Appl. Catal., B, 52, 275-280 (2004).

16) T. Kasahara, K. Inumaru and S. Yamanaka, Microporous Mesoporous Mater., 76, 123-130 (2004).

17) T. Kasahara, K. Inumaru and S. Yamanaka, The 42nd Meeting on Basic Science of Ceramics, 1F04, Jan. (2004) Nagaoka, Japan.
18) K. Inumaru, T. Kasahara, M. Yasui and S. Yamanaka, Chem. Commun. (Camb.), 2131-2133 (2005).

19) K. Inumaru, S. Yamanaka and T. Kasahara, JP2005-314208; Japanese Patent 5194249.

20) K. Inumaru, M. Yasui, T. Kasahara, K. Yamaguchi, A. Yasuda and S. Yamanaka, J. Mater. Chem., 21, 12117-12125 (2011).

21) G. S. Armatas, in "New and Future Developments in Catalysis - Hybrid Materials, Composites, and Organocatalysts", Ed. by S. L. Suib, Elsevier (2013) Chap. 13.

22) S. Namba, N. Hosonuma and T. Yashima, J. Catal., 72, 16-20 (1981).

23) T. Okuhara, M. Kimura and T. Nakato, Appl. Catal., A, 155, L9-L13 (1997).

24) M. Kimura, T. Nakato and T. Okuhara, Appl. Catal., A, 165, 227-240 (1997).

25) K. Inumaru, S. Kakii, H. Yoshida and S. Yamanaka, Chem. Lett., 39, 1215-1217 (2010).

26) $\mathrm{K}$. Inumaru, $\mathrm{T}$. Ishihara, $\mathrm{Y}$. Kamiya, T. Okuhara and $\mathrm{S}$. Yamanaka, Angew. Chem., Int. Ed., 46, 7625-7628 (2007).

27) C. Y. Sun, S. X. Liu, D. D. Liang, K. Z. Shao, Y. H. Ren and Z. M. Su, J. Am. Chem. Soc., 131, 1883-1888 (2009).

$28)$ G. S. Park, D. Shindo, Y. Waseda and T. Sugimoto, J. Colloid Interface Sci., 177, 198-207 (1996).

29) T. Ito, K. Inumaru and M. Misono, J. Phys. Chem. B, 101, 9958-9963 (1997).

30) T. Ito, K. Inumaru and M. Misono, Chem. Mater., 13, 824-831 (2001).

31) S. O. Kim, H. H. Solak, M. P. Stoykovich, N. J. Ferrier, J. J. de Pablo and P. F. Nealey, Nature, 424, 411-414 (2003).

32) H. Colfen and M. Antonietti, Angew. Chem., Int. Ed., 44, 5576-5591 (2005).

33) B. Lee, T. Yamashita, D. L. Lu, J. N. Kondo and K. Domen, Chem. Mater., 14, 867-875 (2002).

34) L. Zhou and P. O'Brien, Small, 4, 1566-1574 (2008).

35) J. Gaude, Y. Laurent, J. Lang and P. Lharidon, Bull. Soc. Fr. Mineral. Cristallogr., 95, 56 (1972).

36) N. E. Brese and M. Okeeffe, J. Solid State Chem., 87, 134-140 (1990).

37) C. M. Fang, G. A. de Wijs, R. A. de Groot, H. T. Hintzen and G. de With, Chem. Mater., 12, 1847-1852 (2000).

38) K. Inumaru, K. Koyama, N. Imo-Oka and S. Yamanaka, Phys. Rev. B, 75, 054416 (2007).

39) K. Sakamoto, K. Inumaru and S. Yamanaka, Appl. Surf. Sci., 199, 303-306 (2002).

40) K. Inumaru, K. Koyama, Y. Miyaki, K. Tanaka and S. Yamanaka, Appl. Phys. Lett., 91, 152501 (2007).

41) K. Inumaru, Y. Miyaki, K. Tanaka, K. Koyama and S. Yamanaka, Phys. Rev. B, 78, 052406 (2008).

42) B. Alling, Phys. Rev. B, 82, 054408 (2010).

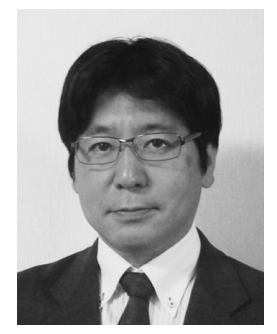

Kei Inumaru was born in 1964. He received his Bachelor's, Master's and Ph. D. degree from the University of Tokyo in 1987, 1989, and 1992, respectively. After working for Mitsubishi Kasei Co. for two years, he began his academic career at the University of Tokyo as a Research Associate. He joined Hiroshima University in 1998 as an Associate Professor and was promoted to Full Professor in 2010. Areas of his research interests include new materials composed of inorganic molecules, porous composite materials for molecular adsorption and (photo)catalysis, superconductors, and magnetic materials. 